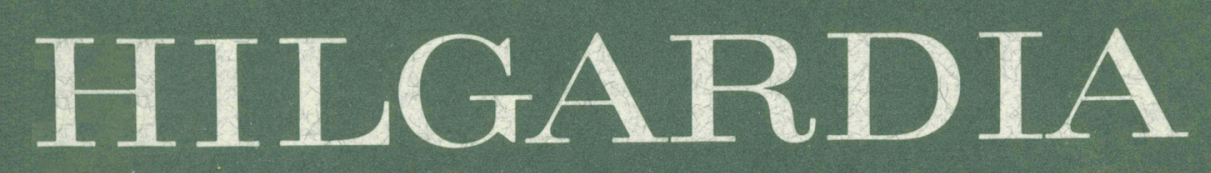

A JOURNAL OF AGRICULTURAL SCIENCE PUBLISHED BY THE CALIFORNIA AGR ICULTURAL EXPERIMENT STATION

Volume 40, Number $16 \cdot$ June, 1971

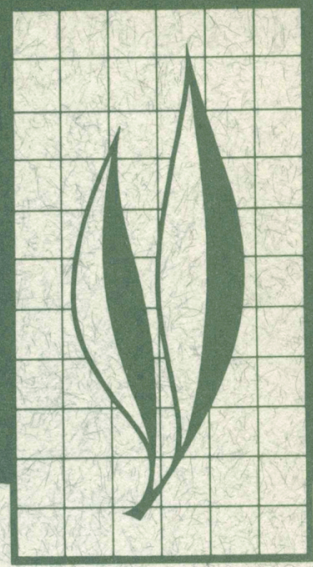

\title{
Effect of Microbial Activity on Saturation Extract Composition
}

R. M. Carlson, Roy Overstreet, and D. V. Naylor 


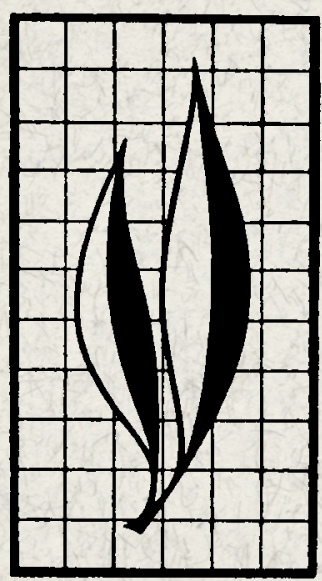

Changes in saturation extract composition caused by microbial production of carbon dioxide were followed by collecting and analyzing fractions of the saturation extracts from Yolo fine sandy loam and eight salt-affected soils. Bicarbonate and cation concentrations increased in the extracts of all but one soil during the course of extraction. Addition of thymol to the soil paste at the time of preparation is recommended to reduce the effects of microbial activity on composition of the saturation extract.

\section{THE AUTHORS:}

R. M. Carlson is Assistant Pomologist in the Experiment Station, Davis.

Roy Overstreet (now deceased) was Professor of Soil Science and Chemist in the Experiment Station, Berkeley.

D. V. Naylor, formerly Research Assistant, Department of Soils and Plant Nutrition, Berkeley, is Assistant Professor of Soils, University of Idaho. 


\section{Effect of Microbial Activity on Saturation Extract Composition $^{1}$}

\section{INTRODUCTION}

IN THE EXAMINATION of salt-affected soils, soluble salts are routinely determined in the solution extracted from a saturated soil paste. Such pastes are most conveniently prepared from soil samples that have been air-dried, ground, sieved, and mixed prior to their examination in the laboratory. Stevenson (1956) has shown that the behavior of the microbial population of remoistened air-dried soil samples can be quite different from that of samples continuously maintained in the moist state. The question of how much microbial activity affects the composition of the saturation extract and how this effect varies as a function of time, after adding water to the air-dry sample, has not been reported in detail.

Various procedures on the handling of saturated pastes before filtration have been recommended. The United States Salinity Laboratory (Richards, 1954) recommends that the paste be allowed to stand for a few minutes before filtration for salinity appraisal in the absence of gypsum. When gypsum is present, they recommend the paste be allowed to stand for several hours; and if the chemical constituents are to be determined, they recommend the paste be allowed to stand from four to 16 hours prior to extraction.

Jackson (1958) recommends a 10 minute standing time before filtration if gypsum is absent and two hours if gypsum is present for salinity appraisal. For the determination of the chemical constituents, he recommends that the paste be allowed to stand for six hours-but no longer-io reach chemical equilibrium because of changes due to microbial activity. Chapman and Pratt (1961) recommended that the paste be allowed to stand for 16 hours before filtration.

It is evident that there is no general agreement on the optimum procedure for handling soil pastes prior to filtration. A few minutes' aging is recommended in the absence of gypsum. Longer aging periods are recommended when gypsum is present to allow the gypsum to equilibrate with the solution. If alkaline earth carbonates are present, they may be slow to equilibrate with the solutions. Equilibration of the paste with carbon dioxide of the atmosphere is probably a slow process. The surge of microbial activity which occurs on rewetting air-dry soil (Stevenson, 1956) may produce sufficient bicarbonate to alter the composition of the extract. The study reported here was undertaken to estimate the magnitude of changes in saturation extract composition due to microbial activity and to seek means of minimizing the influence of microorganisms on extract composition.

\footnotetext{
1 Submitted for publication December 10, 1969.
} 


\section{MATERIALS AND METHODS}

Nine surface soil samples were used in the study. Eight of these samples are from a collection of salt-affected soils from various locations in California; they were selected to include a wide range of $\mathrm{pH}$, exchangeable sodium and soluble salt content. Table 1 indicates

TABLE 1

PROPERTIES OF SALT-AFFECTED SOILS

\begin{tabular}{|c|c|c|c|c|}
\hline \multirow{2}{*}{ Soil no. } & \multicolumn{2}{|c|}{$\mathrm{pH}$ in: } & \multirow{2}{*}{$\begin{array}{c}\text { Elec- } \\
\text { trical } \\
\text { conduc- } \\
\text { tivity of } \\
\text { satura- } \\
\text { tion } \\
\text { extract }\end{array}$} & \multirow{2}{*}{$\begin{array}{l}\text { Ex- } \\
\text { change- } \\
\text { able } \\
\text { sodium }\end{array}$} \\
\hline & $\begin{array}{c}\text { soil } \\
\text { paste }\end{array}$ & $\begin{array}{c}1: 5 \\
\text { suspen- } \\
\text { sion }\end{array}$ & & \\
\hline & & & $\mathrm{mmho} / \mathrm{cm}$ & per cent \\
\hline $2 \ldots \ldots \ldots \ldots$ & 7.4 & 7.6 & 3.8 & 15 \\
\hline $3 \ldots \ldots \ldots$ & 7.6 & 9.1 & 4.3 & 30 \\
\hline $5 \ldots \ldots$ & 9.0 & 9.9 & 6.0 & 82 \\
\hline $6 \ldots \ldots$ & 10.1 & 10.2 & 29.0 & 93 \\
\hline $10 \ldots \ldots \ldots$ & 9.6 & 10.2 & 1.0 & 70 \\
\hline 13. & 6.5 & 6.9 & 1.8 & 14 \\
\hline $22 \ldots \ldots \ldots \ldots$ & 9.7 & 10.2 & 1.4 & 95 \\
\hline $38 \ldots \ldots \ldots \ldots$ & 7.6 & 8.4 & $>20.0$ & 41 \\
\hline $\begin{array}{l}\text { CONTROL: } \\
\text { Yolo fine } \\
\text { sandy loam. }\end{array}$ & . & 7.9 & 0.9 & 1 \\
\hline
\end{tabular}

the ranges in these properties as determined by the procedure given by Richards (1954). The ninth soil was a sample of Yolo fine sandy loam taken from the Davis campus of the University of California. This sample was chosen to represent a productive agricultural soil.
Saturated pastes were prepared with the aid of a single-beater food mixer. After initial mixing, the pastes were allowed to stand for one hour, remixed and transferred to a plastic funnel (Richards, 1949). In one case, 36 hours elapsed between initial mixing and filtration. The weight of paste on the filter was determined so that the fraction of the saturation moisture extracted could be calculated. The extract was collected in fractions, and the time required for extraction of each fraction was recorded in most cases. When microbial inhibitors were used, they were added at the time of paste preparation. One sample of Yolo fine sandy loam was sterilized by 20 -hour exposure to an atmosphere of ethylene oxide gas before the paste was prepared.

Chemical analyses were performed on individual extract fractions. Sodium and potassium were determined with a Beckman Model DU flame spectrophotometer. Calcium and magnesium determinations were by chelometric titration. Chloride was titrated potentiometrically with silver nitrate. Bicarbonate was titrated with sulfuric acid. No effort was made to distinguish carbonate from bicarbonate, so the bicarbonate data is the sum of the milliequivalents of bicarbonate and carbonate ions.

\section{RESULTS}

\section{Yolo fine sandy loam}

Figure 1 shows the ionic composition of fractions of the saturation extract of Yolo fine sandy loam. No microbial inhibitors were added to this paste. The exact times of extraction of each fraction were not recorded. The first three fractions were collected the day extraction began. The extraction of the fourth fraction was completed the day after extraction began, and the fifth fraction was completed the second day after filtration began. The chloride concentration remained constant during extraction, while the bicarbonate increased continuously during the course of extraction. The concentrations of all cations increased during the course of extraction, as would be expected from a shift of cation exchange equilibria, with the addition of carbonic acid to the system. 
Figure 2 shows the composition of extract fractions collected from a saturated paste of Yolo fine sandy loam, which aged at room temperature for 36 hours before extraction. The first three

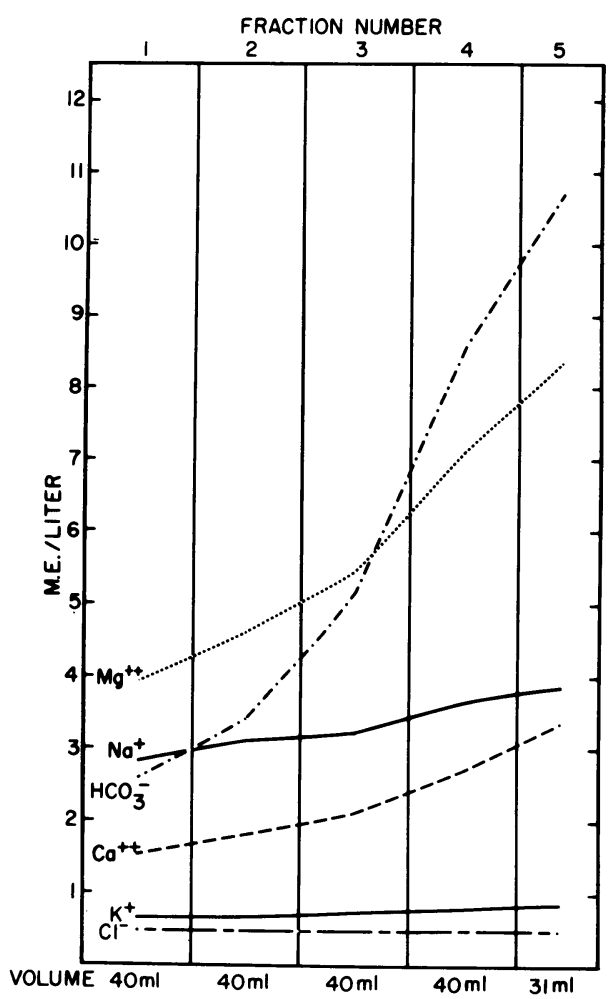

Fig. 1. Composition of saturation extract fractions of Yolo fine sandy loam. 1,385 gm paste extracted, sat. $\mathrm{Pw} 40.0$ percent, 48.0 percent recovery of saturation moisture.

fractions were collected the day extraction began, and the extraction of the fourth fraction was completed the day after extraction began. The concentrations of bicarbonate and cations in the initial fractions from this paste were greater than in the initial fractions of the paste extracted one hour after preparation.

Bicarbonate concentration was constant in the first three fractions, then increased in the fourth fraction. Between the completion of the third and fourth fraction, the paste cracked from shrinkage allowing entry of air. There was a slight increase in cation concen- tration during the course of extraction, which suggests a slow solution equilibria of sparingly soluble salts.

The influence of temperature on changes in extract composition was

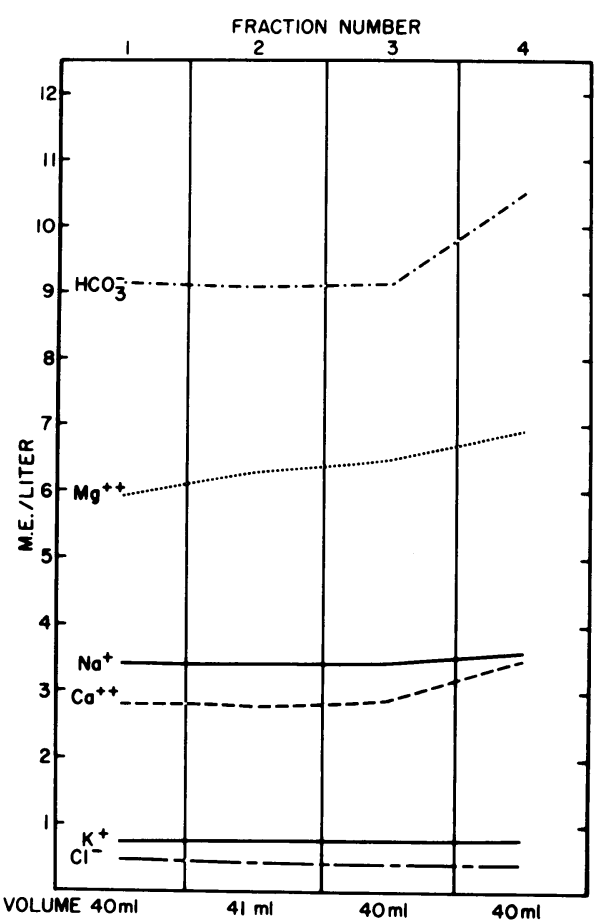

Fig. 2. Composition of saturation extract fractions of Yolo fine sandy loam. 1,096 gm paste (aged 36 hours) extracted, sat. Pw 40.8 percent, 51.0 percent recovery of saturation moisture.

studied by extracting refrigerated paste of Yolo fine sandy loam. The air-dry soil, water, mixing apparatus, and filter assembly were stored in a laboratory refrigerator for two days before preparation of the paste, and extraction was carried out in the refrigerator. The inhibition of microbial production of carbon dioxide by low temperature was shown by the lower bicarbonate in the first fraction, and smaller increase in bicarbonate during the course of extraction of this paste (fig. 3) compared to the paste extracted at room temperature (fig. 1). Comparison of cation concentrations in these two pastes show similar trends. 
Formaldehyde, thymol, and toluene were studied as materials which might be added to the saturated paste to inhibit microbial activity. These materials were added to individual pastes at the time of preparation. An additional

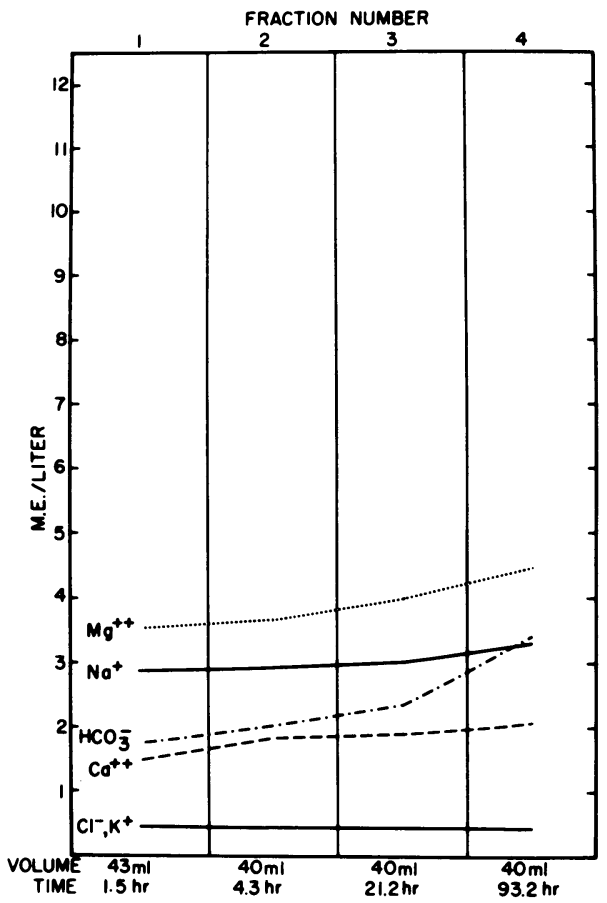

Fig. 3. Composition of saturation extract fractions of Yolo fine sandy loam. 1,242 gm refrigerated paste extracted, sat. $\mathrm{Pw} 37.5$ percent, 48.0 percent recovery of saturation moisture.

paste was prepared with the addition of both thymol and toluene. The rates of addition were $1 \mathrm{ml}$ formaldehyde (37 per cent), $1 \mathrm{gm}$ thymol, or $1 \mathrm{ml}$ toluene per kg air-dry soil. The pastes were remixed one hour after preparation and extracted as before. The analyses of the extract fractions are presented in figures $4,5,6$, and 7 for the formaldehyde, thymol, toluene and thymol plus toluene-treated pastes, respectively. The formaldehyde and thymol treatments were very effective in reducing the increase in bicarbonate during the course of extraction. The bicarbonate concentration was higher in the first two fractions from the thymol-treated paste than in the corresponding fractions from the formaldehyde-treated paste. There appeared to be no change in bicarbonate during the course of extraction of the thymol treatment, while

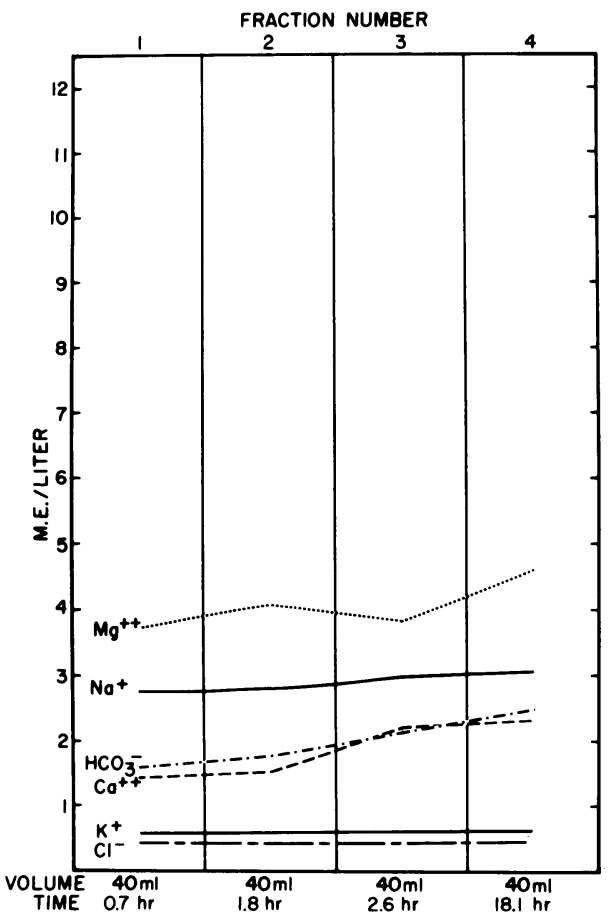

Fig. 4. Composition of saturation extract fractions of Yolo fine sandy loam treated with formaldehyde. $1,225 \mathrm{gm}$ paste extracted, sat. Pw 39.2 percent, 46.0 percent recovery of saturation moisture.

some increase in bicarbonate did occur in the formaldehyde treatment. Toluene reduced bicarbonate production in the first three fractions, but lost its effectiveness by the time the fourth fraction was collected. The thymol plus toluene treatment eliminated change in bicarbonate in the first three extract fractions, but not in the fourth fraction. Of the four treatments, the thymol appears to give the best control of microbial activity.

An additional sample of Yolo fine sandy loam was sterilized by exposure in the air-dry state to an atmosphere of 
ethylene oxide gas for 20 hours prior to preparation of the paste. The analysis of extract fractions from this paste is presented in figure 8 . This treatment almost eliminated production of bicarbonate. However, it would not be as convenient as the thymol treatment for routine analysis of soils. Note that this treatment had almost eliminated

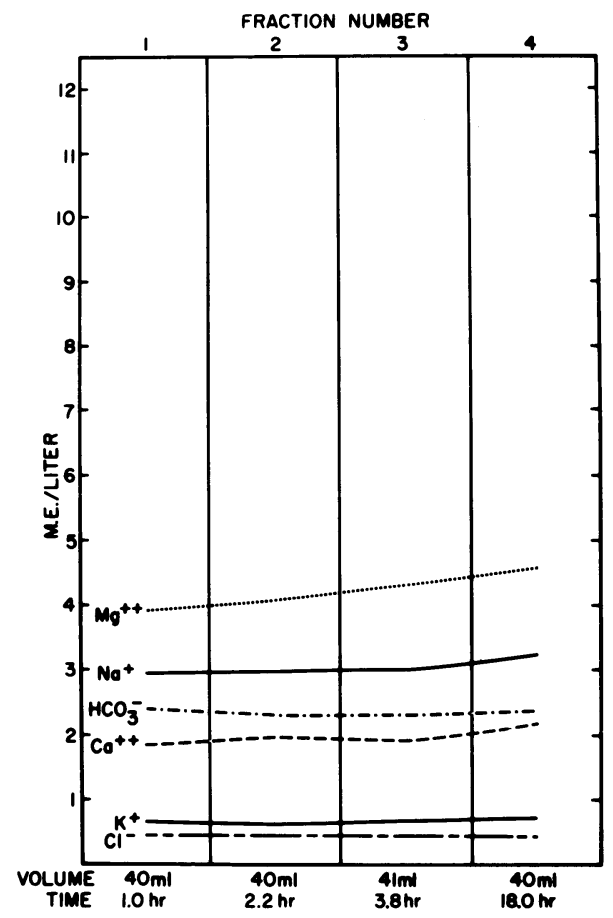

Fig. 5. Composition of saturation extract fractions of Yolo fine sandy loam treated with thymol. 1,243 gm paste extracted, sat. Pw 40.3 percent, 45.0 percent recovery of saturation moisture.

chloride ion from the extract. The ethylene oxide may have combined with the chloride to form either a volatile compound or a chloride-containing compound which does not titrate with silver ion.

\section{Salt-affected soils}

The results of the study of the Yolo soil indicated that the addition of thymol might be a convenient and effective means of controlling microbial activity in soil pastes. Extract fractions of satu-

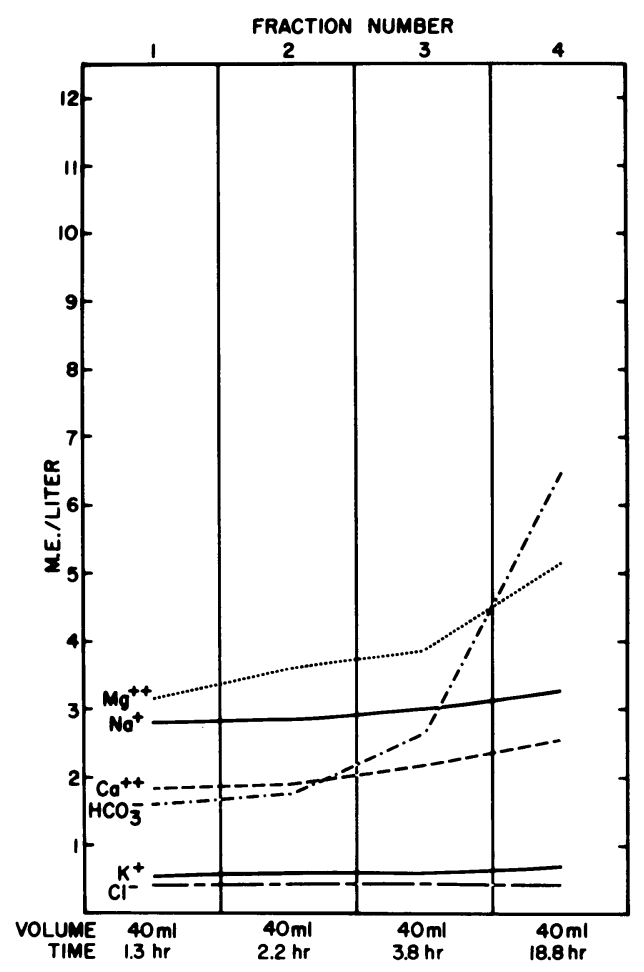

Fig. 6. Composition of saturation extract fractions of Yolo fine sandy loam treated with toluene. $1,236 \mathrm{gm}$ paste extracted, sat. $\mathrm{Pw}$ 39.0 percent, 46.0 percent recovery of saturation moisture.

rated pastes of the salt-affected soils prepared with and without addition of thymol were analyzed to determine the extent of microbial activity and the effectiveness of thymol as an inhibitor in these soils. As with the Yolo soil, $1 \mathrm{gm}$ thymol was added per kg of dry soil, and the pastes were allowed to stand for one hour before beginning the extraction.

Figures 9 and 10 show the analyses of the extracts of soil no. 2. This soil is a borderline case with respect to salt content and exchangeable sodium content (table 1). The bicarbonate concentration increased more than four-fold from the first to the fourth fraction. Soluble cations increased in a corresponding manner. Addition of thymol to this soil reduced but did not eliminate the increase in bicarbonate ion. 


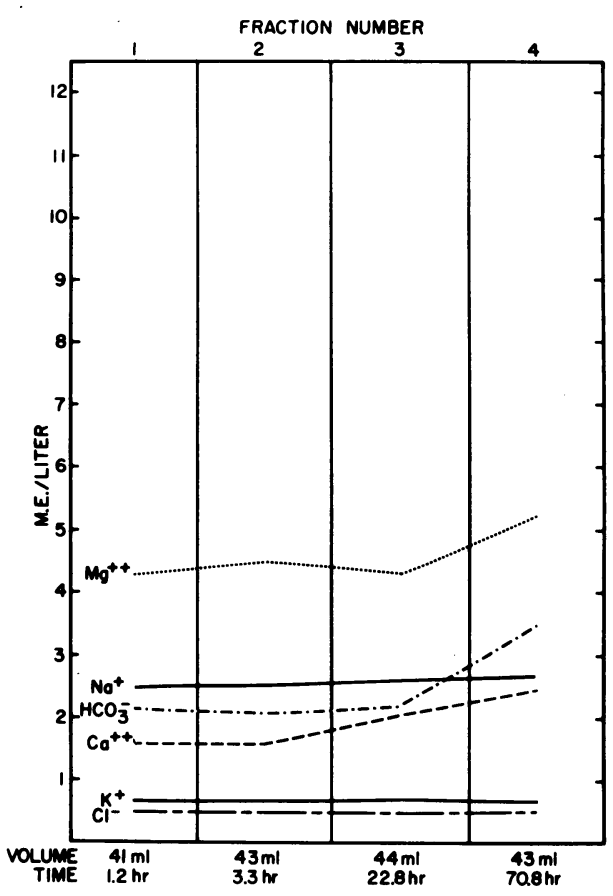

Fig. 7. Composition of saturation extract fractions of Yolo fine sandy loam treated with toluene and thymol. 1,238 gm paste extracted, sat. Pw 38.4 percent, 50.0 percent recovery of saturation moisture.

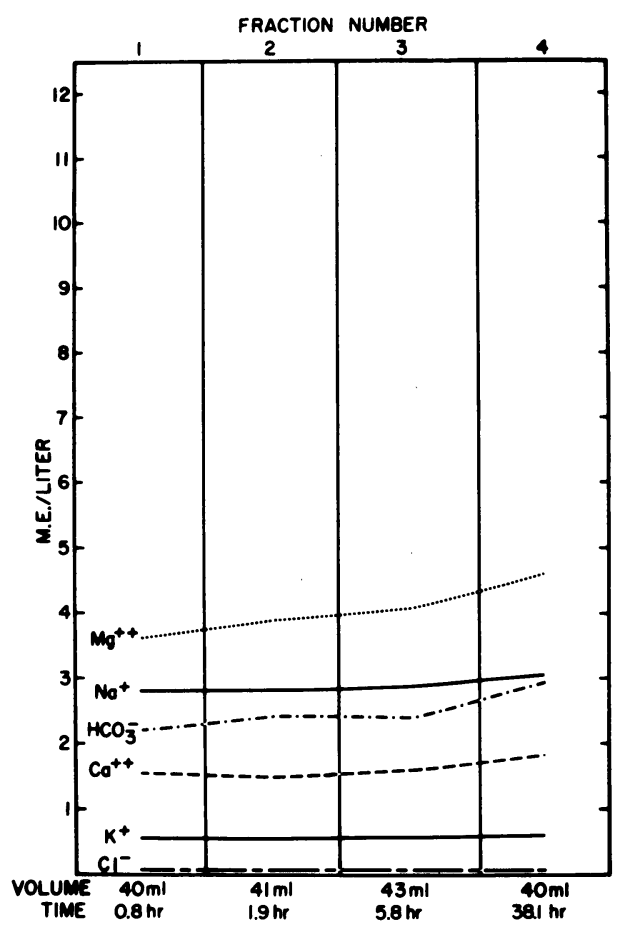

Fig. 8. Composition of saturation extract fractions of Yolo fine sandy loam treated with ethylene oxide. $1,173 \mathrm{gm}$ paste extracted, sat. Pw 36.9 percent, 53.0 percent recovery of saturation moisture.

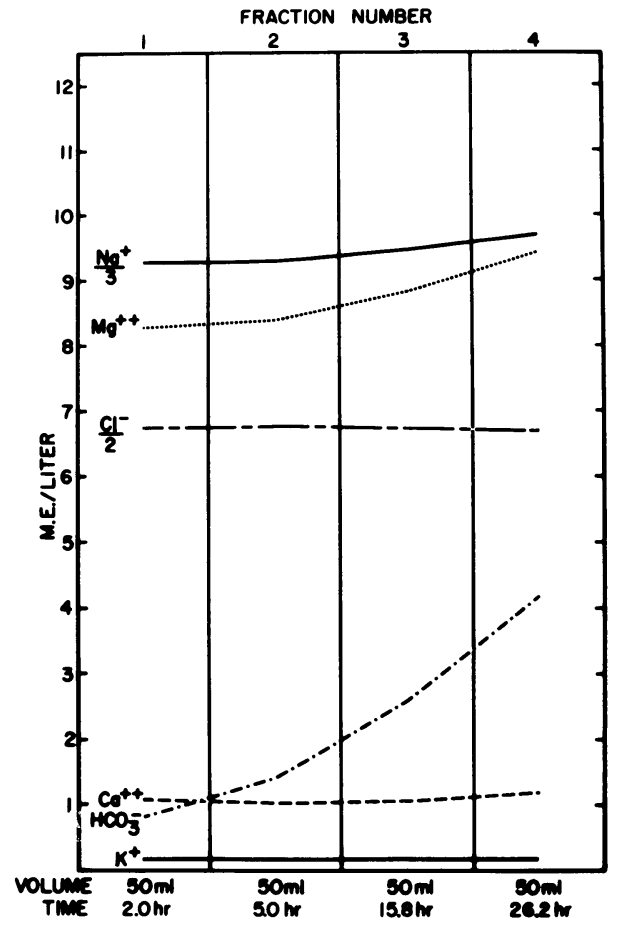

Fig. 9. Composition of saturation extract fractions of soil no. 2. 1,451 gm paste extracted, sat. Pw 83.8 percent, 30.0 recovery of saturation moisture.

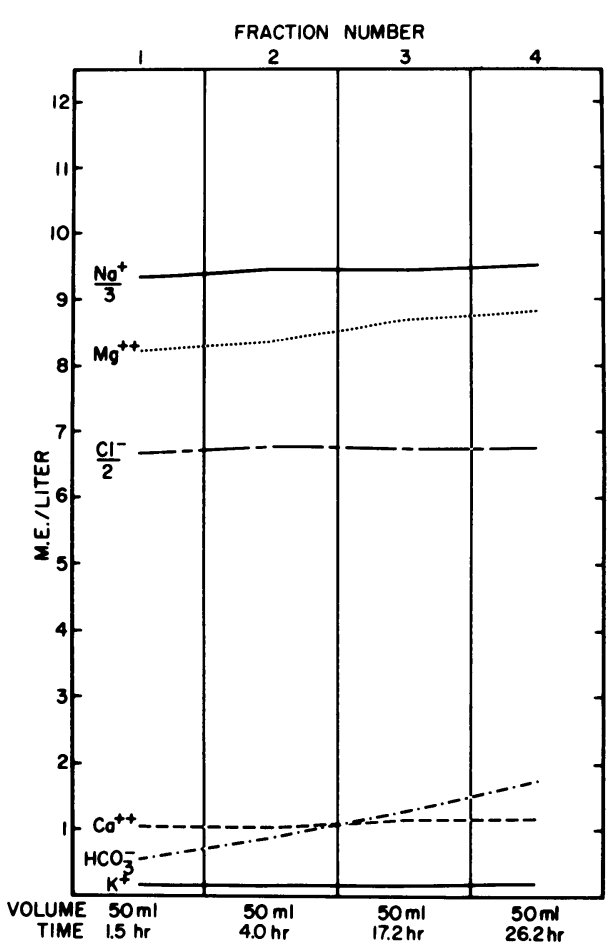

Fig. 10. Composition of saturation extract fractions of soil no. 2 treated with thymol. 1,493 gm paste extracted, sat. $\mathrm{Pw} 82.6$ percent, 30.0 percent recovery of saturation moisture. 


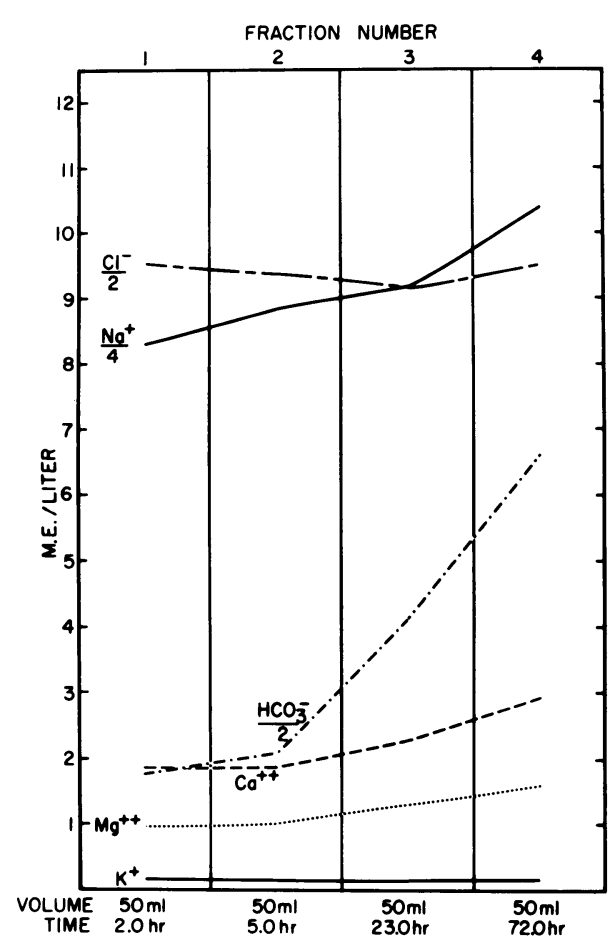

Fig. 11. Composition of saturation extract fractions of soil no. $3.1,258 \mathrm{gm}$ paste extracted, sat. Pw 43.3 percent, 53.0 percent recovery of saturation moisture.

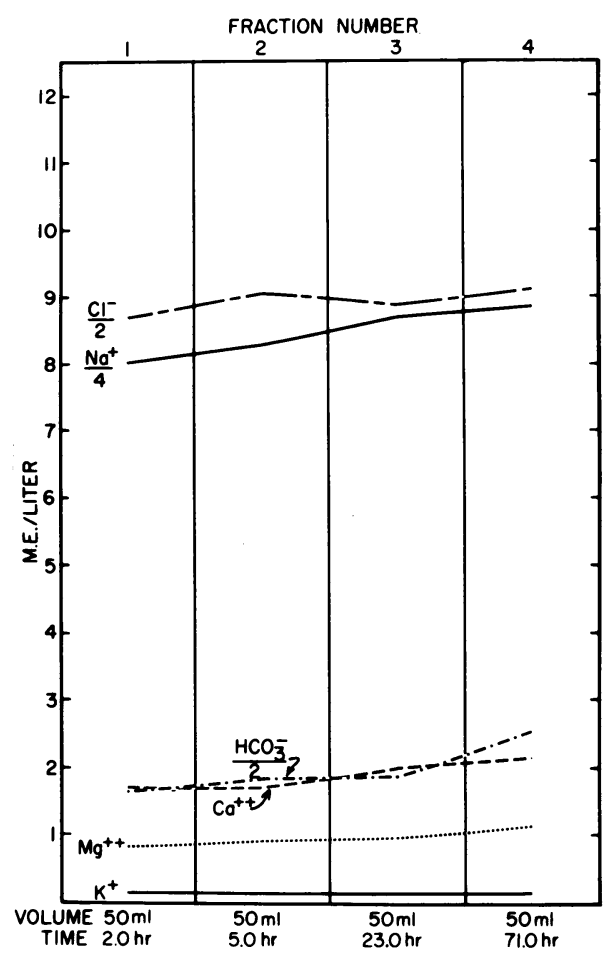

Fig. 12. Composition of saturation extract fractions of soil no. 3 treated with thymol. 1,294 gm paste extracted, sat. Pw 43.0 percent, 51.0 percent recovery of saturation moisture.

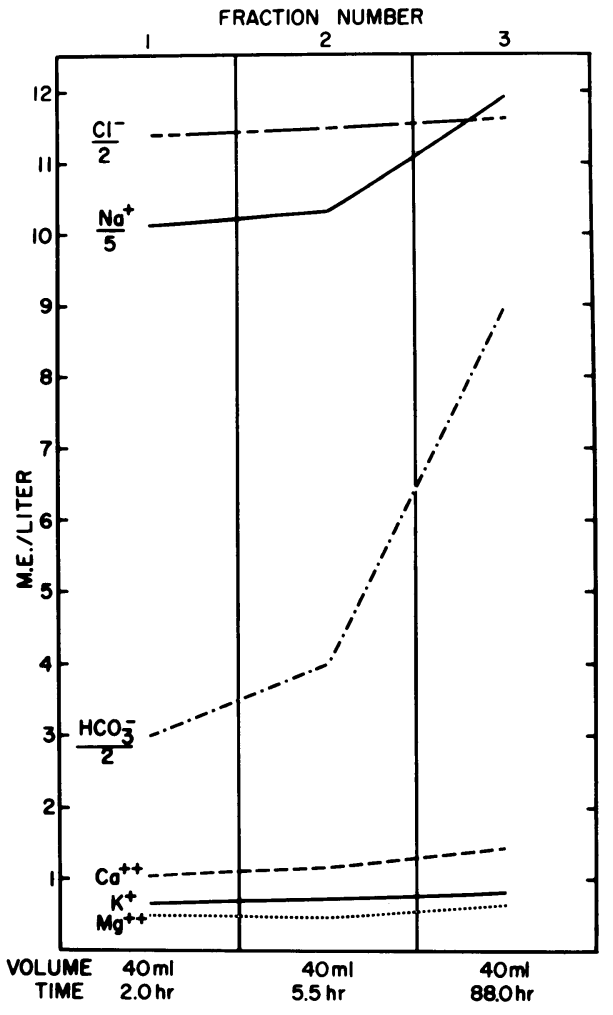

Fig. 13. Composition of saturation extract fractions of soil no. $5.1,139 \mathrm{gm}$ paste extracted, sat. $\mathrm{Pw} 31.1$ percent, 44.0 percent recovery of saturation moisture.

Soil no. 3 had a borderline salt content with 30 per cent exchangeable sodium. The data for this soil are given in figures 11 and 12. Without thymol, bicarbonate increased more than threefold during the course of extraction. Thymol was very effective in reducing microbial activity in this soil.

Soil no. 5 had a moderately high salt content with very high exchangeable sodium and $\mathrm{pH}$. Bicarbonate concentration of the last fraction was three times that of the first fraction without the addition of thymol (fig. 13). When thymol was added (fig. 14), bicarbonate in the last fraction was only about onethird greater than that of the first fraction. Even in the presence of thymol, sodium increased more than can be accounted for by the increase in bicarbonate. This was probably due to the slow dissolution of silicate and/or aluminate salts. 


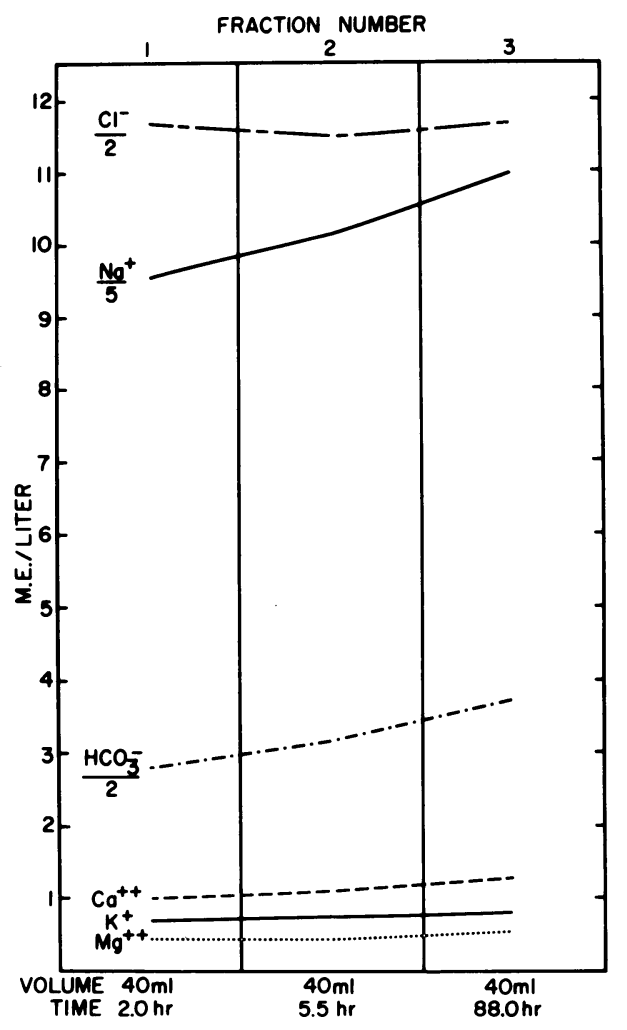

Fig. 14. Composition of saturation extract fractions of soil no. 5 treated with thymol. 1,160 gm paste extracted, sat. $\mathrm{Pw} 31.4$ percent, 44.0 percent recovery of saturation moisture.

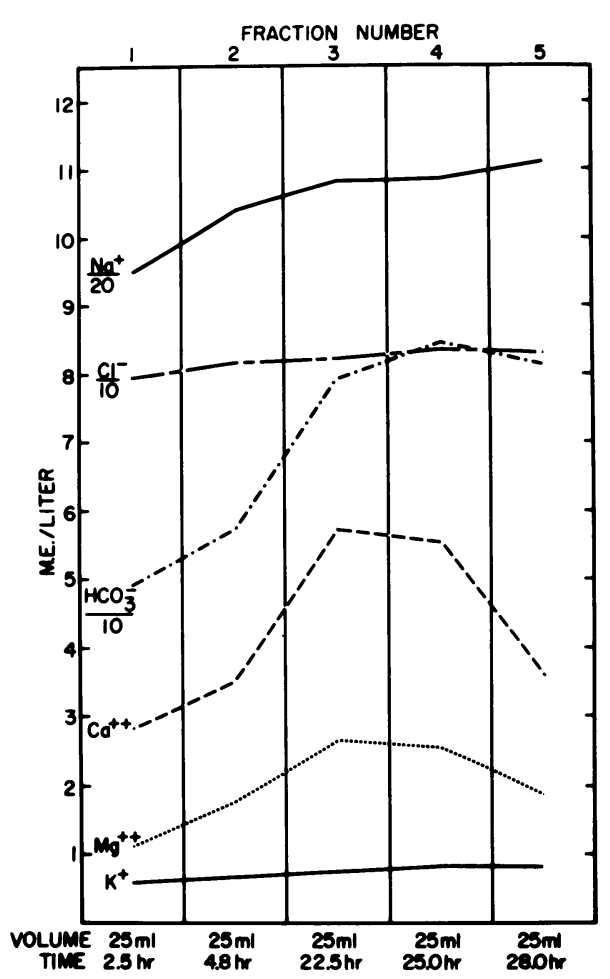

Fig. 15. Composition of saturation extract fractions of soil no. 6. 1,225 gm paste extracted, sat. $\mathrm{Pw}_{\mathrm{w}} 40.4$ percent, 36.0 percent recovery of saturation moisture.

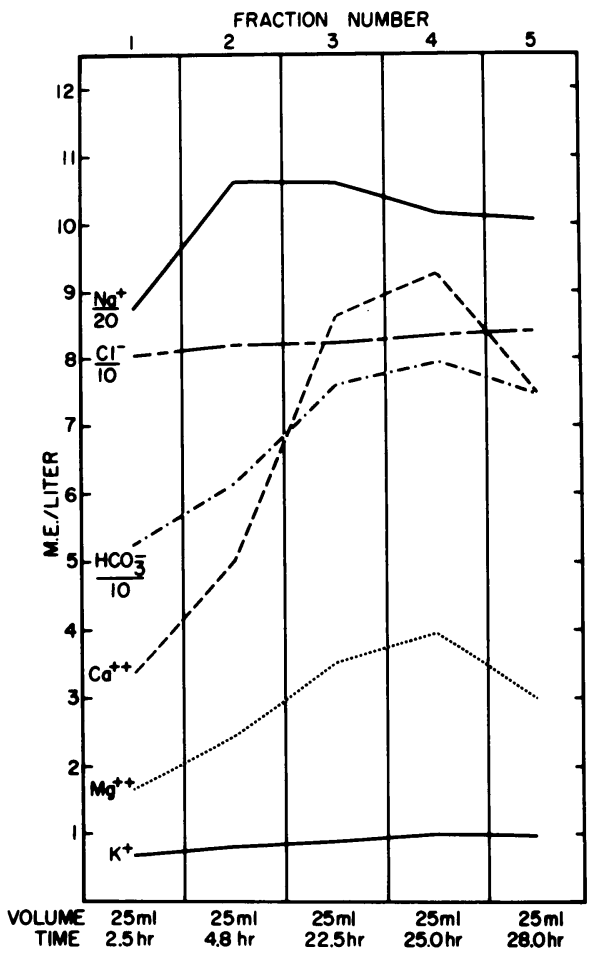

Fig. 16. Composition of saturation extract fractions of soil no. 6 treated with thymol. 1,249 gm paste extracted, sat. $\mathrm{Pw} 40.3$ percent, 35.0 percent recovery of saturation moisture.

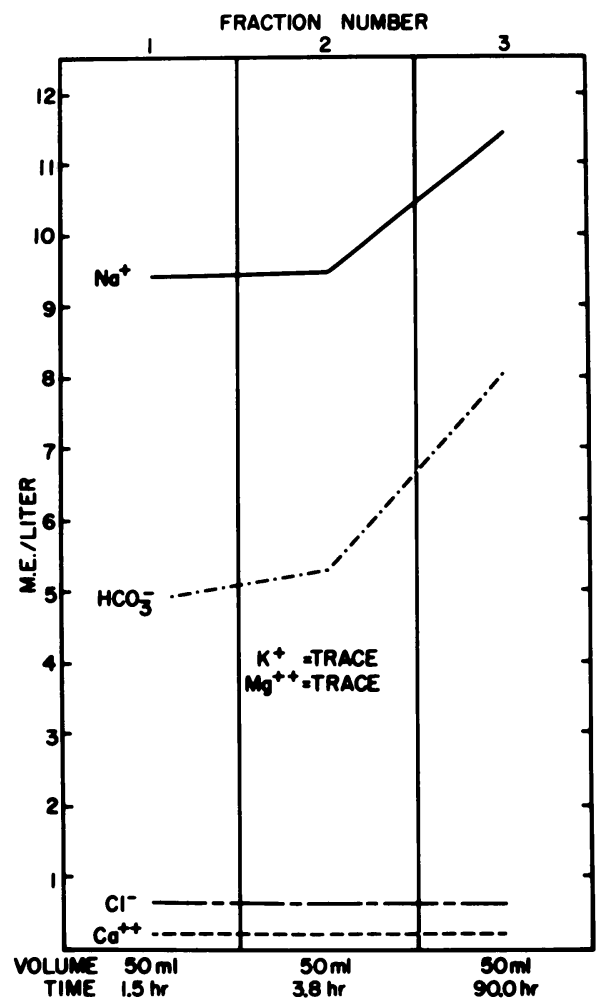

Fig. 17. Composition of saturation extract fractions of soil no. 10. 1,160 gm paste extracted, sat. Pw 30.4 percent, 56.0 percent recovery of saturation moisture. 


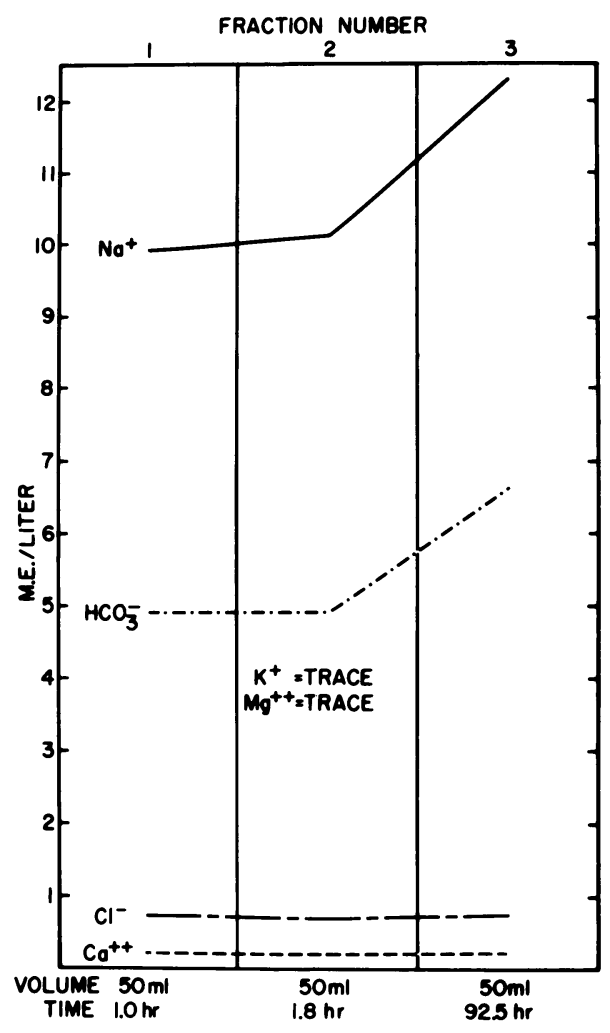

Fig. 18. Composition of saturation extract fractions of soil no. 10 treated with thymol. 1,174 gm paste extracted, sat. Pw 30.9 percent, 54.0 percent recovery of saturation moisture.

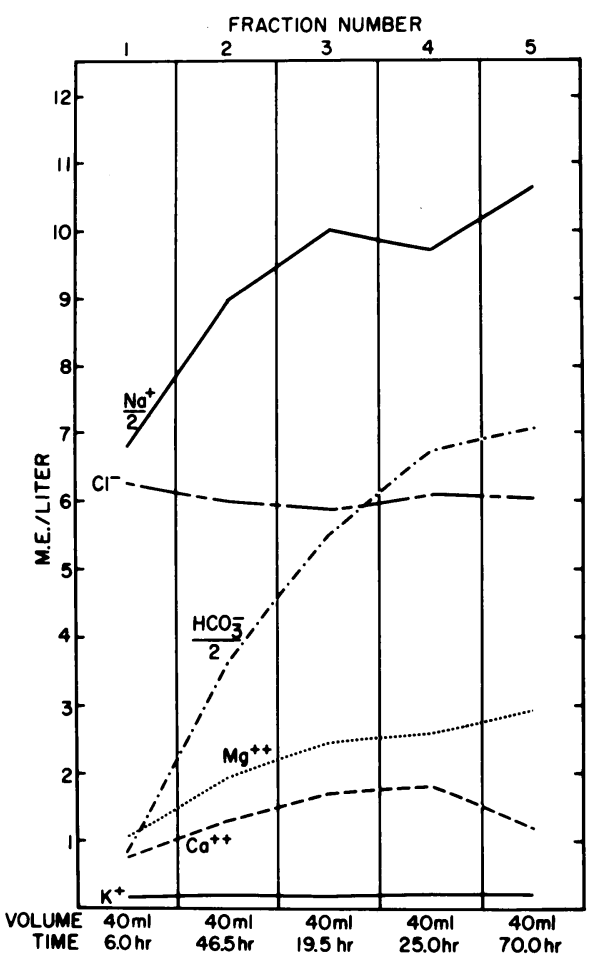

Fig. 19. Composition of saturation extract fractions of soil no. 13. 1,445 gm paste extracted, sat. $\mathrm{Pw} 54.8$ percent, 39.0 percent recovery of saturation moisture.

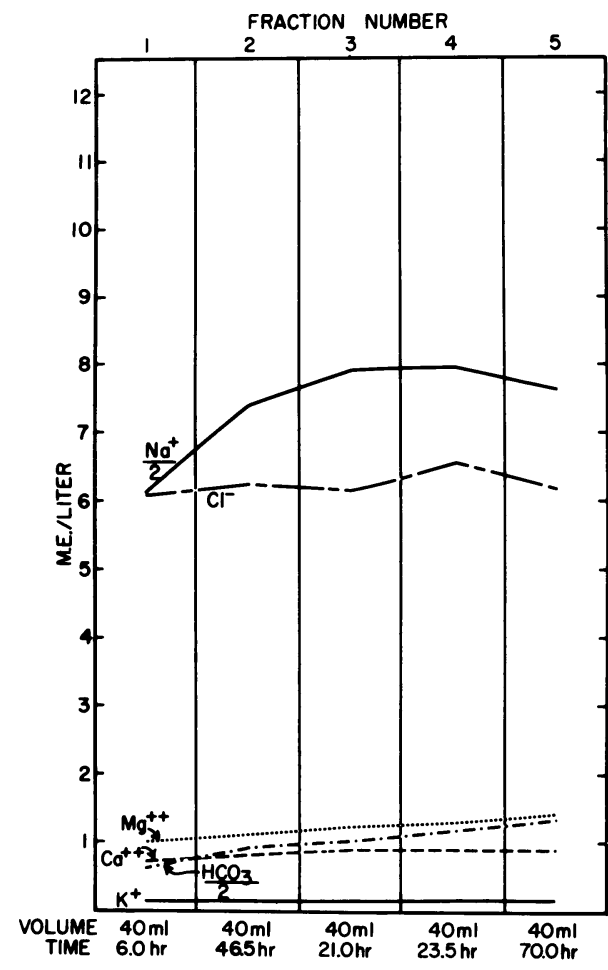

Fig. 20. Composition of saturation extract fractions of soil no. 13 treated with thymol. 1,477 gm paste extracted, sat. Pw 54.8 percent, 38.0 percent recovery of saturation moisture.

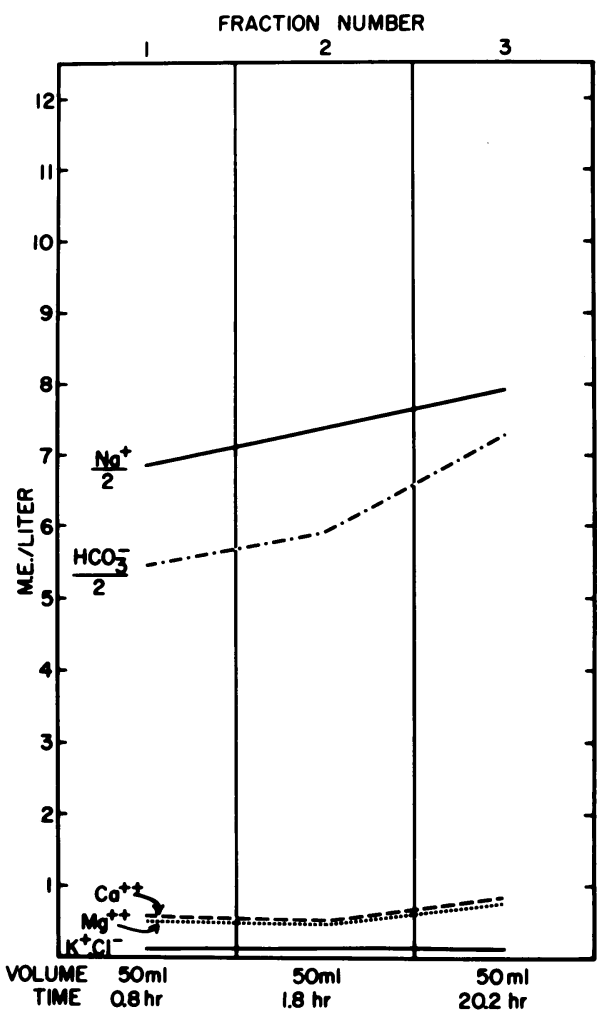

Fig. 21. Composition of saturation extract fractions of soil no. 22. 1,176 gm paste extracted, sat. $\mathrm{Pw} 33.1$ percent, 51.0 percent recovery of saturation moisture. 


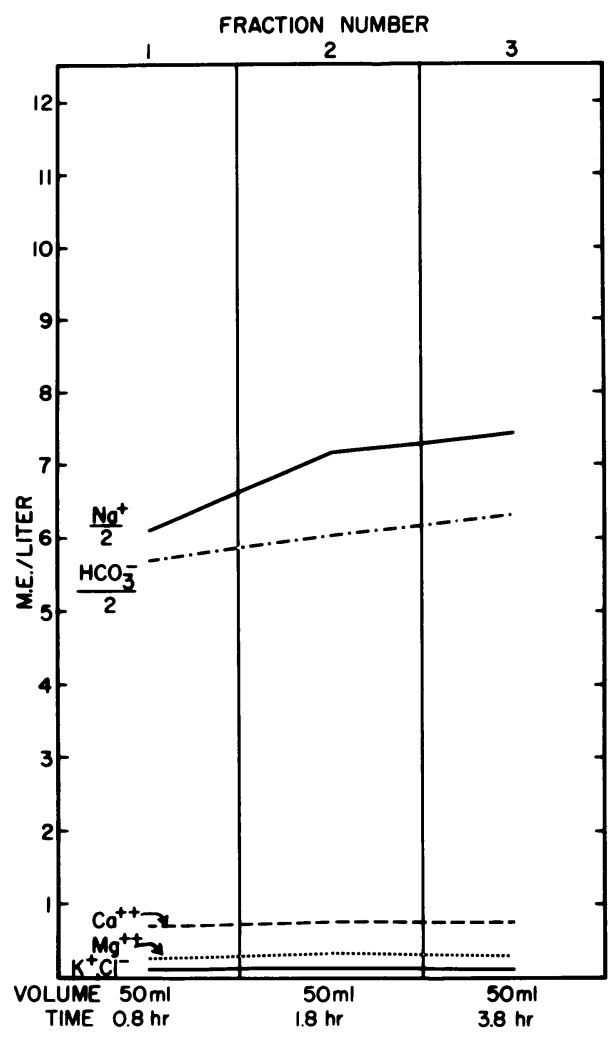

Fig. 22. Above, composition of saturation extract fractions of soil no. 22 treated with thymol. 1,176 gm paste extracted, sat. $\mathrm{Pw}$ 33.6 percent, 51.0 percent recovery of saturation moisture.

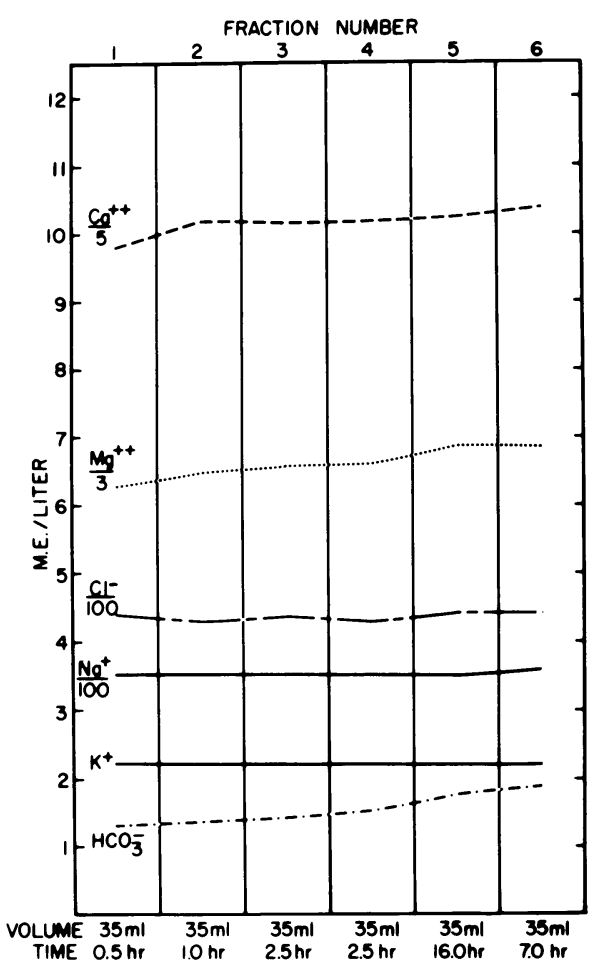

Fig. 23. Below, composition of saturation extract fractions of soil no. 38. 1,371 gm paste extracted, sat. Pw 57.0 percent, 42.0 percent recovery of saturation moisture.

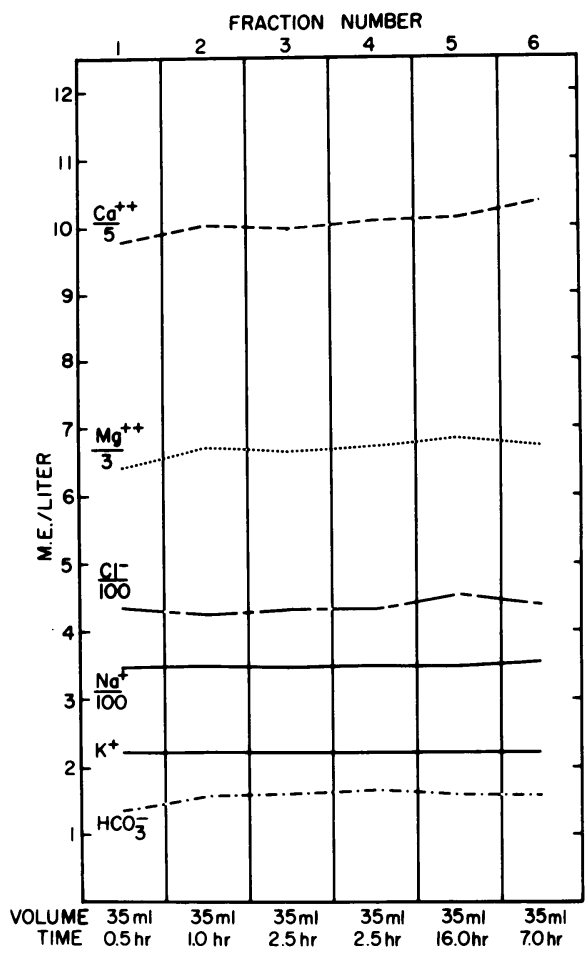

Fig. 24. Composition of saturation extract fractions of soil no. 38 treated with thymol. 1,372 gm paste extracted, sat. Pw 57.4 percent, 42.0 percent recovery of saturation moisture.

Soil no. 6 (figs. 15 and 16) showed an extremely high salt content, high $\mathrm{pH}$, and high exchangeable sodium content. Bicarbonate concentrations in successive fractions increased substantially then leveled off both in the absence and presence of thymol. Calcium and magnesium increased to maxima, then decreased, the effect being greater in the presence of thymol.

Soil no. 10 (figs. 17 and 18) was a low-salt, high $\mathrm{pH}$, high exchangeable sodium soil. Three extract fractions were collected, the third requiring a rather long period of extraction. Bicarbonate increased slightly from the first to the second fraction in the untreated paste, but not in the thymol-treated paste. Bicarbonate increased from the second to the third fraction in both pastes, but the increase was less in the thymol treatment than in the paste without thymol.

Soil no. 13 (figs. 19 and 20) was 
neutral in reaction with moderate salt and borderline exchangeable sodium percentage. Without thymol, bicarbonate increased seven-fold during the course of extraction. In the presence of thymol there was a much smaller increase in bicarbonate. In the thymol treatment, sodium concentration increased to an extent that could not be accounted for by the increase in bicarbonate.

Soil no. 22 (figs. 21 and 22) had a low salt content, very high $\mathrm{pH}$, and was almost saturated with sodium. Bicarbonate increased in successive extract fractions from both the control and thymol-treated pastes.

Soil no. 38 (figs. 23 and 24) represented an extreme case of high salinity with chloride in the saturation extract more than 0.4 normal. This soil was also high in exchangeable sodium. Change in bicarbonate concentration in extract fractions was not large either with or without the addition of thymol.

\section{DISCUSSION}

The concentration of bicarbonate and cations increased in the successive extract fractions of all soils not treated with a microbial inhibitor, with the exception of soil no. 38. The high concentration of sodium chloride in soil no. 38 may be effective as a microbial inhibitor. The chloride concentration was nearly constant during the course of extractions, which indicated that salt sieving was not the cause of the increases in the concentrations of the other ions. Carbon dioxide produced by micro-organisms would dissolve to produce carbonic acid. Hydrogen ion from the carbonic acid would replace exchangeable cations, resulting in increased concentration of bicarbonate salts in solution. The reduction of the increase in concentration of bicarbonate salts during extraction by the various treatments used to control microbial activity indicated that microbial activity was an important factor in the observed changes of extract composition.

Thymol did not completely eliminate changes in extract composition in most of the soils studied. It may be that thymol does not completely eliminate microbial activity. It is also likely that there are soil components which come to equilibrium with the solution very slowly. This appeared to be the case with soil no. 6 . This soil had a very high $\mathrm{pH}$ and was very high in exchangeable sodium. It seems likely that the complicated changes in extract composition of this soil were due more to phase transitions (aluminates, silicates, carbonates) than to microbial activity. Any aluminate or silicate in the extract of this soil would be titrated along with bicarbonate and it may be that the increase in bicarbonate in the extract from the thymol-treated paste of this soil (fig. 15) was mostly due to the titration of aluminate and/or silicate in extract. This soil requires further study to clarify the behavior of its saturation extract.

It is evident that microbial activity causes significant increases in the concentration of bicarbonate salts in soil pastes. The analysis of the saturation extract of a soil will vary depending upon the time elapsed between preparation of the paste and initiation of filtration, time required to collect an adequate volume of extract, and temperature. Results from soils studied in this work indicate that bicarbonate concentration in the paste continues to increase for many hours after the paste is prepared. As the rate of change in bicarbonate differs from soil to soil, it would be difficult to select some arbitrary time to allow the paste to age between preparation and initiation of extraction which would be reasonable for all soils. 
The addition of thymol to the soil at the time of paste preparation offers a convenient means to reduce or eliminate microbial production of carbon dioxide during the course of aging and extracting the paste. Stevenson (1956) reports that microbial activity in a soil sample which has been air-dried and then remoistened is greater than in a sample of the same soil which has not been air-dried. Thus, the analysis of an extract obtained from a paste containing thymol is probably as good an estimate of the condition existing in the field as the analysis of an extract obtained by current procedures. The addition of thymol makes the time element much less critical and, if generally adopted, should make the analysis of saturation extracts more reproducible.

\section{LITERATURE CITED}

Chapman, H. D., and P. F. Pratt

1961. Methods of analysis for soils, plants, and waters. Division of Agricultural Sciences, University of California. $309 \mathrm{pp}$.

JACKSON, M. L.

1958. Soil chemical analysis. Englewood Cliffs, New Jersey: Prentice-Hall, Inc. 498 pp.

Richards, L. A.

1949. Filter funnels for soil extracts. Agron. Jour. 41:446.

1954. (Ed.) Diagnosis and improvement of saline and alkali soils. U. S. Dept. Agr. Handbook No. $60.160 \mathrm{pp}$.

Stevenson, I. L.

1956. Some observations on the microbial activity in remoistened air-dried soils. Plant and Soil 8:170-82. 
(x) 
The journal HILGARDIA is published at irregular intervals, in volumes of about 650 to 700 pages. The number of issues per volume varies.

Single copies of any issue may be obtained free, as long as the supply lasts; please request by volume and issue number from:

\section{Agricultural Publications \\ University of California \\ Berkeley, California 94720}

The limit to nonresidents of California is 10 separate titles. The limit to California residents is 20 separate titles.

The journal will be sent regularly to libraries, schoole, or institutions in one of the following ways:

1. In exchange for similar published material on research.

2. As a gift to qualified repository libraries only.

3. On a subscription basis $-\$ 7.50$ a year paid in advance. All subscriptions will be started with the first number issued during a calendar year. Subscribers starting during any given year will be sent back numbers to the first of that year and will be billed for the ensuing year the following January. Make checks or money orders payable to The Regents of The University of California; send payment with order to Agricultural Publications at above address. 